\title{
Compreensão textual em alunos de segunda e terceira séries: uma abordagem cognitiva
}

\author{
Jerusa Fumagalli de Salles \\ Centro Universitário Franciscano \\ Maria Alice de Mattos Pimenta Parente \\ Universidade Federal do Rio Grande do Sul
}

\begin{abstract}
Resumo
Este estudo teve como objetivo analisar a compreensão de leitura textual de alunos de $2^{\mathrm{a}}$ e $3^{\mathrm{a}}$ séries. Participaram 76 crianças, com média de idade de 8,1 anos. Cada criança lia a história, recontava-a e, posteriormente, respondia a questões. Os recontos foram analisados segundo o Modelo de Compreensão Textual de Kintsch \& van Dijk (1978) e Kintsch (1988, 1998). A amostra relatou, em média, 21,07\% da estrutura proposicional da história, sendo mais freqüente o relato de macroproposições. Alunos da terceira série foram superiores aos da segunda série no relato de microproposições menos relevantes do texto e em responder a questões pontuais sobre a história. Foi encontrada uma correlação significativa entre idade e o reconto da macroestrutura textual. Os resultados sugerem que durante os primeiros anos de escolarização ocorreu uma melhora da memorização de detalhes, enquanto que a retenção das idéias essenciais foi influenciada pelas variações de idade das crianças.
\end{abstract}

Palavras-chave: compreensão textual; leitura; reconto de histórias; avaliação de leitura

\begin{abstract}
Text comprehension in second and third graders: a cognitive approach. This study aimed to analyze text comprehension of students of the $2^{\text {nd }}$ and $3^{\text {rd }}$ grades. The sample was constituted by 76 children, at an average of 8.1 years old. Each child read the story, retold it and, afterwards, answered questions about it. The retellings were analyzed according to the model of Text Comprehension of Kintsch and van Dijk (1978) and Kintsch $(1988,1998)$. The sample recalled a mean of $21.07 \%$ of the proposition structure of the story, being the report of macropropositions more frequent. Students of the third grade told larger percentage of irrelevant micropropositions of the text and they were superior in answering to specific questions than students of the second grade. A significant correlation was found between age and macroproposition's retelling. The results suggest that during the first years of schooling there is an improvement of the detail-remembering, whereas the retention of the essential ideas is influenced by age differences.
\end{abstract}

Key-words: text comprehension; reading; story retelling; reading evaluation

A leitura é uma atividade complexa que envolve a intervenção de diversos processos: identificação de letras, reconhecimento de palavras, acesso ao significado, integração sintática e semântica. Embora seja verdadeiro que a identificação das palavras é necessária para compreender um texto, ela poderia não ser suficiente (Alégria, Leybaert, \& Mousty, 1997). Quanto mais rápida é a identificação de cada palavra, a memória de trabalho tem maiores disponibilidades de recursos para realizar operações de análise sintática, de integração semântica dos constituintes da frase e de integração das frases na organização textual, processos importantes para a compreensão da leitura (Morais, 1996).

A literatura sugere vários outros processos cognitivos relacionados à compreensão de leitura, além da habilidade em identificação de palavra, como memória de trabalho (Engle,
Cantor, \& Carullo, 1992; Swanson \& Alexander, 1997; Waters \& Caplan, 1996), exposição à escrita, conhecimento do vocabulário, metacognição (Cain, 1999; McBridge, Manis, Seidenberg, Custodio, \& Doi, 1993), habilidades semânticas (Nation \& Snowling, 1998), consciência sintática (Gaux \& Gombert, 1999), além de processos que também são usados para a compreensão da linguagem falada, incluindo o conhecimento geral sobre o tema tratado no texto (Ellis, 1995).

Braibant (1997) propõe três fatores essenciais para explicar a presença de dificuldades de compreensão, quando as capacidades de identificação de palavras são eficientes: (1) capacidades lingüísticas (vocabulário, sintaxe) e cognitivas (elaboração de inferências) insuficientes; (2) falta de automatização na captação de informação escrita e (3) incapacidade para adaptar suas estratégias ao objetivo procura- 
do, ou seja, privilegiar a exatidão da decodificação em detrimento da busca de um sentido geral mais amplo do que a palavra isolada.

Os modelos inicialmente propostos para analisar a compreensão textual, segundo Ruíz-Vargas (1995), focalizavam a estrutura do texto, como, por exemplo, a Gramática de Histórias de Stein e Glen (1976). Gramática de Histórias é um tipo de análise de narrativas, caracterizada por um conjunto formal de regras que descrevem a formação de histórias como algo previsível. Posteriormente, os estudos começaram a considerar o papel do processo construtivo que o leitor realiza durante a compreensão, destacando-se aqui o modelo descrito por Kintsch e van Dijk (1978) e revisado, posteriormente, por Kintsch $(1988,1998)$.

Segundo o Modelo de Compreensão Textual de Kintsch e van Dijk (1978), devido às limitações na memória de curto prazo, o processamento de um texto é feito em ciclos, que correspondem, aproximadamente, a uma frase, numa espécie de resumo das informações relevantes. Nestes ciclos, uma estrutura mais geral de significado, a macroestrutura, é extraída das proposições do texto original e mantida na memória episódica junto com os itens finais do ciclo. As frases apresentadas no texto são conhecidas como microestruturas. $\mathrm{O}$ ciclo seguinte altera as representações dos anteriores na memória episódica, fazendo com que ocorra a construção gradual de um texto base, que depende dos conhecimentos prévios que o indivíduo tem, armazenados na memória episódica.

A compreensão de um texto ou discurso implica a criação de um texto base, que organiza hierarquicamente todas as proposições explícitas no texto. Textos base combinam duas fontes de informação: conhecimento sobre linguagem, bem como conhecimento sobre o mundo (Kintsch, 1988). A construção do texto base, que permite ao leitor relatar as proposições contidas na história, implica a elaboração de uma série de inferências que proporcionam a coerência semântica local entre proposições (Graesser, Swamer, Baggett, \& Sell, 1996).

As proposições incluídas no conteúdo de um texto não são recordadas igualmente, e talvez não se processem com a mesma profundidade ou a mesma atenção. Há uma tendência de se recordar as idéias mais importantes, ou seja, a macroestrutura textual (Carmona, González, \& Gómez, 1992).

A noção de macroestrutura é empregada por Kintsch e van Dijk (1978) para definir a descrição semântica do conteúdo global do discurso. Pode ser entendida como uma organização de significado que representa os aspectos essenciais de um texto, por meio de unidades denominadas macroproposições. A compreensão seria um processo que permite elaborar a macroestrutura do texto a partir de sua microestrutura.

Van Dijk e Kintsch (1983, citados por Denhière \& Baudet, 1992) distinguem três níveis na representação do discurso: (1) a estrutura de superfície (palavras e sintagmas do texto); (2) o conteúdo semântico local (microestrutura) e global (macroestrutura) e (3) o modelo de situação. Neste último, não é o texto que é representado, mas a situação que é descrita no texto, retirada da estrutura do texto e encaixada no campo de conhecimentos pré-estabelecidos.
Segundo Kintsch (1988), os modelos de situação, sob certas circunstâncias, podem ser como os modelos mentais, ou seja, um construto localizado na memória episódica que contém a representação subjetiva do texto: inferências e experiências prévias. Durante o processo de compreensão textual, inúmeras inferências devem ser feitas pelo leitor (Leffa, 1996). O texto base contém inferências que possibilitam uma coerência semântica local entre proposições e o modelo de situação ou modelo mental é uma representação mental de pessoas, lugares, ações, objetivos e eventos que estão explicitamente mencionados ou inferencialmente sugeridos no texto (Graesser et al., 1996).

Inferências baseadas no conhecimento são aquelas que são construídas quando estruturas de conhecimento da memória de longo-prazo são ativadas e incorporadas na representação do significado do texto (Graesser et al., 1996). Dentre os modelos de inferências na compreensão textual, podemos citar o de Graesser et al. (1996), que propõem seis tipos de inferências: objetivo superordenado, ação/objetivo subordinado, antecedente causal, conseqüência causal, emoção do personagem e estado/situação. Ao invés de classificar os tipos de inferências feitas no reconto, Cadilhac, Virbel e Nespoulous (1997) propõem uma análise do reconto de texto na qual dividem as proposições recontadas não originais da história em inferências, interferências e reconstruções.

Os estudos sobre compreensão textual em crianças, em geral, utilizam dois tipos de recursos metodológicos de investigação: a reprodução (oral ou escrita) de um texto apresentado e respostas a perguntas sobre um texto lido ou ouvido pela criança (Brandão \& Spinillo, 1998, 2001). Parte das pesquisas nacionais sobre compreensão textual tem enfocado a análise da compreensão oral de textos (Brandão \& Spinillo, 1998, 2001; Dias, 2000). A compreensão de leitura textual em crianças foi analisada por alguns autores brasileiros (Dias, Morais, \& Oliveira, 1995; Goes \& Aragão, 1992; Mello, 1988; Rego, 1995; Salles \& Parente, 2002; Salles, Parente, Alexandre, Xavier, \& Fernandes, 2001). Favero e Trajano (1998) estudaram a compreensão textual em adolescentes, enquanto Kopcke Filho (1997), Rodrigues, Dias e Roazzi (2002) e Santos (1990, 1991), em universitários, e Parente, Capuano e Nespoulous (1999) e Parente, Saboskinski, Ferreira e Nespoulous (1999), em idosos. Boruchovitch (2001) e Jou (2001) analisaram as estratégias de compreensão de leitura em alunos do Ensino Fundamental.

Segundo Brandão e Spinillo (1998), crianças mais novas mostram-se menos fiéis ao texto que lhes é apresentado, incluindo elementos de outras histórias. No estudo de Brandão e Spinillo (2001), crianças de 8 anos apresentaram desempenho superior na tarefa de compreensão oral de textos do que as crianças mais novas (4 e 6 anos de idade). As autoras concluem que a compreensão de textos é uma habilidade que se desenvolve entre as idades de 4 e 8 anos. A maior capacidade de recordação pode decorrer do aumento gradual da capacidade de processamento de informações com a idade e escolarização (Flavell, Miller, \& Miller, 1999) ou de um vínculo entre o desenvolvimento lingüístico e psicológico do indivíduo Poersch (1994, citado por Chiele, 1996). 
Embora exista um consenso de que o nível de compreensão em leitura aumenta sistematicamente à medida que a criança avança em faixas de idade/escolaridade, os estudos acima citados não verificaram se a retenção das estruturas internas do texto (macroestrutura e proposições que denotam detalhes) apresenta um desenvolvimento paralelo ou dissociado. Por serem estruturas que envolvem, segundo a teoria de Kintsh e van Dijk (1978), processos cognitivos diversos, uma análise dessas estruturas durante o início da escolarização não apenas poderá contribuir para os conhecimentos do desenvolvimento da compreensão textual, como também tais achados podem ser úteis para o estabelecimento de propostas educativas.

Desta forma, este estudo teve como objetivo analisar as habilidades de compreensão textual de crianças de $2^{\underline{a}}$ e $3^{\underline{a}}$ séries do Ensino Fundamental, através do Modelo de Compreensão Textual de Kintsch e van Dijk (1978) e Kintsch (1988, 1998), observando o desenvolvimento da memorização de histórias e da incorporação nos recontos de proposições pertencentes à macroestrutura e das proposições que se referem a detalhes.

\section{Método}

\section{Participantes}

Participaram deste estudo 76 crianças, de ambos os sexos, com idades entre 6:9 e 9:4 anos (média =8,1), estando 40 (52,6\%) delas em início de segunda e 36 (47,4\%), em início de terceira série do Ensino Fundamental de uma escola particular da cidade de Porto Alegre, RS. A média de idade foi de 7,6 anos, na amostra de segunda série, e de 8,6 anos, na amostra de terceira série. Na segunda série, 77,5\% das crianças tinham idade inferior a 8 anos. Na terceira série, 100\% das crianças eram maiores de 8 anos.

A amostra caracterizou-se por crianças de classe socioeconômica média-alta, não repetentes na escola; sem queixas de problemas auditivos ou dificuldades visuais não corrigidas e com linguagem expressiva oral dentro dos padrões considerados normais para a idade. Todas as crianças estavam autorizadas pelos pais ou responsáveis a participar da pesquisa.

\section{Material e procedimentos específicos}

A compreensão de leitura foi avaliada de duas formas: através da reprodução oral da história lida e através da resposta a questões de múltipla escolha sobre a história. Cada criança era solicitada a ler silenciosamente uma história, com aproximadamente 200 palavras de extensão e níveis apropriados de legibilidade para o nível de escolaridade da amostra. A história “A coisa” foi adaptada do texto de Rocha (1997) para este estudo. Era informado à criança que ela deveria posteriormente recontar a história e, em seguida, responder a questões sobre a mesma.

O reconto da história pela criança foi solicitado em primeiro lugar para estar o mais isento possível de interferências. Fornecer as opções de respostas, através das questões de múltipla escolha, poderia ser um índice de conteúdo para o reconto da história. Esta ordem de apresentação das tarefas tem sido estabelecida em estudos sobre compreensão textual (Brandão \& Spinillo, 1998, 2001).

No reconto oral da história, imediatamente após leitura, cada criança foi instruída a recontar a história com a maior quantidade de detalhes possível. Os recontos foram gravados e posteriormente transcritos para serem analisados segundo o Modelo de Compreensão Textual de Kintsch e van Dijk (1978) e Kintsch (1988, 1998). Neste modelo, o significado do texto original é representado através de uma lista estruturada de proposições, que são classificadas, conforme sua importância para a compreensão da história, como fazendo parte apenas da microestrutura (detalhes menos relevantes) ou também da macroestrutura (idéias essenciais) do texto. A história “A coisa” foi dividida, através de acordo entre quatro juizes, em 61 proposições, sendo 23 (37,7\% da estrutura) consideradas como integrando a macroestrutura e 38 (62,3\% da estrutura) a microestrutura menos relevante do texto (Apêndice A).

No reconto de cada criança, as proposições do texto original relatadas foram classificadas em: porcentagem total de proposições presentes, porcentagem de proposições da macroestrutura e porcentagem de proposições da microestrutura menos relevante relatadas. As proposições emitidas nos recontos que não estavam presentes na história original foram classificadas em inferências, interferências ou reconstruções, como proposto por Cadilhac et al. (1997).

Foram consideradas inferências, os comentários pertinentes a respeito de fatos presentes na história original, utilização de uma supercategoria semântica (ex.: velho para avô) ou relato de um fato que deve ter acontecido na história, mas que está ausente no texto original. Exemplos de inferências realizadas neste estudo: "Pedro desceu as escadas no escuro”; “Não era um monstro era só um reflexo do espelho”; "Sabe porque saía luz da barriga? Porque botavam no meio do espelho e voltava a luz da lanterna”; "Pedro subiu apavorado".

Consideraram-se interferências casos em que a criança modificava o significado das proposições da história por ter associado em uma mesma proposição dois elementos presentes na história, mas independentes. Ocorreu uma reconstrução quando houve a introdução de proposições que relatavam fatos não presentes na história original e que não poderiam ser inferidos pelas informações contidas no texto (Parente et al., 1999b). Exemplos de interferências realizadas nos recontos: "Todo dia quando eles desciam a escada, viam um espelho”; "E daí eles viram que tinha uma escada”; "Viu um monstro segurando a lanterna indo embora"; "Viu um monstro que tinha olhos parecidos com espelhos”; "Uma coisa que tinha um monte de espetos na cabeça”. Exemplos de reconstruções: "Tinha um fantasma na casa do vô"; "O fantasma assustava todo mundo”; “O Lucas”... (ao invés de Pedro); “O gurizinho foi no sítio”; “Abriu a janela e o fantasma saiu”; "Pedro foi procurar um skate”; "Viu que era um espantalho”.

O questionário era composto por 10 perguntas sobre a história, cada uma delas acompanhada de cinco itens-resposta de múltipla escolha (Apêndice B). Metade das ques- 
tões propostas estavam relacionadas com memória para eventos e caracteres descritos na própria história (memória para eventos) e a outra metade avaliava compreensão inferencial (motivos implícitos, reações, etc.). O examinador lia oralmente para a criança as questões e as respectivas opções de resposta, enquanto a mesma podia acompanhar a leitura visualmente. Os resultados desta tarefa foram apresentados em termos de médias de porcentagem de questões respondidas corretamente.

\section{Análise dos dados}

Os dados foram analisados de forma quantitativa. Para analisar o desempenho da amostra em compreensão de leitura textual segundo a série escolar, foi aplicado um teste estatístico para comparação de grupos (Análise de Variância). Foram também conduzidas análises de correlações (coeficiente de Pearson) entre as avaliações.

\section{Resultados}

A análise descritiva do desempenho da amostra em compreensão de leitura textual é apresentada na Tabela $1 . \mathrm{Na}$ análise do reconto da história pela criança, pode-se perceber que os participantes relataram, em média, 21,07\% da estrutura proposicional geral da história. Os recontos apresentaram maior porcentagem de macroproposições $(M=31,92 \%)$ do que de microproposições ( $M=14,51 \%$ ) menos relevantes da história. Além disso, os mesmos continham maior número de inferências e menor número de reconstruções e de interferências.

Alguns exemplos de inferências realizadas pelos alunos no reconto da história, considerando a classificação proposta por Graesser et al. (1996), foram: objetivo superordenado: "Pedro queria andar de patins ou brincar com patins”; ação/objetivo subordinado: "Pedro caminhou até o porão"; antecedente causal: "Pedro viu o fantasma ou monstro”; conseqüência causal: “Alguém desvendou o mistério do fantasma ou monstro”, "Pedro não conseguiu pegar os patins”, "o vovô achou que era mentira do Pedro que ele tinha visto um fantasma”; emoção do personagem: "Pedro se assustou”, "Pedro ficou apavorado”, "Pedro ficou com medo", "a vovó Julinha não acreditava em monstro"; estado/ situação: "O fantasma era assustador", "Pedro era um gurizinho”, “no porão era escuro”, “depois que dona Julinha abriu a última janela o porão ficou iluminado”.

Houve uma elevada variabilidade interindividual nos resultados do reconto da história, evidenciada tanto pelo desvio padrão quanto pela amplitude das médias de porcentagem de proposições, macroproposições e microproposições menos relevantes recontadas. Considerando a macroestrutura da história, houve casos em que nenhuma macroproposição foi relatada, em contraposição a casos em que mais da metade da macroestrutura da história foi recontada (ver Tabela 1).

O número de inferências, interferências e reconstruções presentes nos recontos também mostrou variabilidade importante. Enquanto algumas crianças não relataram nenhum fato além do que estava explicitamente exposto na história, outras inseriram no reconto mais de cinco elementos extras.

A Tabela 2 mostra o desempenho da amostra em compreensão de leitura textual, segundo a série escolar. Na comparação de grupos, segundo a série escolar, observou-se diferença estatisticamente significante entre as médias de porcentagem de microproposições menos relevantes relatadas $\left(F_{(1,70)}=4,24 ; p<0,05\right)$. Alunos da terceira série relataram maior média de porcentagem de proposições da microestrutura menos relevante do texto do que alunos da segunda série.

Em relação às médias da porcentagem de proposições recontadas, a diferença de desempenho entre as séries foi quase estatisticamente significativa $\left(F_{(1,70)}=3,69 ; p=0,59\right)$. Alunos da terceira série apresentaram desempenho superior ao dos alunos da $2^{\underline{a}}$ série. No reconto da macroestrutura relevante da história e nas médias do número de inferências, interferências e reconstruções não houve diferença significativa entre alunos de cada série.

Na tarefa de responder a questões sobre a história, pode-se perceber que a amostra, de forma geral, apresentou desempenho elevado, respondendo corretamente $81,71 \%$ das questões propostas. O desempenho foi levemente superior para as questões de memória para eventos descritos na his-

Tabela 1

Estatística descritiva da amostra $(n=76)$ nas avaliações de compreensão de leitura textual - reconto de história e resposta às questões

\begin{tabular}{lrrcc}
\hline \multicolumn{1}{c}{ Avaliações } & Média & DP & Mínimo & Máximo \\
\hline Proposições relatadas (\%) & 21,07 & 10,98 & 3,28 & 57,38 \\
Macroproposições relatadas (\%) & 31,92 & 16,93 & 0 & 78,26 \\
Microproposições relatadas (\%) & 14,51 & 9,31 & 2,63 & 44,74 \\
Número inferências no reconto & 2,26 & 1,63 & 0 & 8 \\
Número interferências no reconto & 1,24 & 1,24 & 0 & 6 \\
Número reconstruções no reconto & 1,38 & 1,46 & 0 & 7 \\
Questões memória de eventos (\%) & 83,16 & 20,67 & 40,0 & 100 \\
Questões compreensão inferências (\%) & 80,26 & 23,89 & 0 & 100 \\
Total compreensão de questões (\%) & 81,71 & 19,49 & 20,0 & 100 \\
\hline
\end{tabular}


Tabela 2

Média e desvio padrão da porcentagem/número de acertos nas tarefas que avaliam compreensão de leitura textual - reconto de história e resposta a questões, segundo a série escolar.

\begin{tabular}{|c|c|c|c|}
\hline & $2^{-a}$ série & $3^{\text {a }}$ série & amostra total \\
\hline & Média $\pm D P$ & Média $\pm D P$ & Média $\pm D P$ \\
\hline Proposições (\%) & $17,54 \pm 9,26^{\mathrm{a}}$ & $25,00 \pm 11,51^{\mathrm{a}}$ & $21,07 \pm 10,98$ \\
\hline Macroproposições (\%) & $26,41 \pm 14,81^{\mathrm{a}}$ & $38,04 \pm 17,21^{\mathrm{a}}$ & $31,92 \pm 16,93$ \\
\hline Microproposições (\%) & $12,17 \pm 8,42^{\mathrm{a}}$ & $17,10 \pm 9,67^{b}$ & $14,51 \pm 9,31$ \\
\hline $\mathrm{N}^{\mathrm{o}}$ Inferências & $1,95 \pm 1,85^{\mathrm{a}}$ & $2,61 \pm 1,27^{\mathrm{a}}$ & $2,26 \pm 1,63$ \\
\hline $\mathrm{N}^{\mathrm{o}}$ Interferências & $1,15 \pm 1,05^{\mathrm{a}}$ & $1,33 \pm 1,43^{a}$ & $1,24 \pm 1,24$ \\
\hline $\mathrm{N}^{o}$ Reconstruções & $1,10 \pm 1,26^{\mathrm{a}}$ & $1,69 \pm 1,62^{a}$ & $1,38 \pm 1,46$ \\
\hline Memória eventos (\%) & $80,00 \pm 22,19^{a}$ & $86,67 \pm 18,52^{b}$ & $83,16 \pm 20,67$ \\
\hline Compreensão inferencial (\%) & $74,50 \pm 26,40^{a}$ & $86,67 \pm 19,12^{\mathrm{a}}$ & $80,26 \pm 23,89$ \\
\hline Total compreensão questões (\%) & $77,25 \pm 20,88^{a}$ & $86,67 \pm 16,73^{b}$ & $81,71 \pm 19,49$ \\
\hline
\end{tabular}

Nota: as médias ( \pm desvio padrão) seguidas de letras iguais $\left({ }^{\mathrm{a}, \mathrm{b}}\right)$ não diferem significativamente ao nível de $5 \%$

tória do que para questões envolvendo inferências. Entretanto, a variabilidade nos resultados foi visível, principalmente nas questões que envolviam elaboração de inferências.

Novamente houve diferença estatisticamente significante entre as médias de acertos dos alunos de $2^{\underline{a}}$ e $3^{\text {a }}$ séries no total do teste de compreensão de questões $\left(F_{(1,70)}=\right.$ 5,06; $p<0,05)$ e, especificamente, nas questões de memória para eventos descritos na história $\left(F_{(1,70)}=5,21 ; p<0,05\right)$. Em ambas as medidas, as médias de acertos das crianças de terceira série foram significativamente superiores às médias das crianças de segunda série.

Nas questões de compreensão textual que envolviam inferências, as diferenças de desempenho entre alunos de $2^{\underline{a}}$ e $3^{\underline{a}}$ séries foram visíveis, porém não estatisticamente significativas $\left(F_{(1,70)}=2,9 ; p=0,09\right)$. Novamente, o desempenho dos alunos de $3^{\underline{a}}$ série foi superior ao dos da $2^{\underline{a}}$ série.

As correlações entre as avaliações são expostas na Tabela 3. O fator idade correlacionou-se significativamente, mas de forma fraca, apenas com porcentagem de proposições e macroproposições da história relatadas. As crianças mais velhas relataram maior porcentagem de proposições e de macroproposições da história.

O escore total no teste de compreensão de questões sobre a história correlacionou-se com porcentagem de proposições, macroproposições e microproposições menos relevantes, além de correlacionar-se fortemente com as questões que o constituem (memória para evento e compreensão inferencial). É interessante ressaltar que os testes que avaliavam compreensão de leitura textual (reconto da história e compreensão de questões) apresentaram uma correlação moderada entre si. Isto nos remete a pensar a respeito da validade destes instrumentos em avaliar o que foram idealizados para avaliar, ou seja, um processo cognitivo e lingüístico comum: a compreensão da linguagem, neste caso, escrita.
O número de inferências presentes nos recontos correlacionou-se com porcentagem de proposições e de microproposições menos relevantes, enquanto que o número de reconstruções correlacionou-se também com porcentagem de macroproposições. Inferências e reconstruções estavam correlacionadas entre si.

\section{Discussão}

As crianças desse estudo relataram, em média, 20\% da estrutura proposicional geral da história. Em estudos experimentais (Kintsch, 1977) foram encontrados que os sujeitos retêm aproximadamente de 10 a 25\% de uma história, reproduzindo não apenas um fragmento do texto original, mas também uma versão mais abstrata. A melhor recordação da macroestrutura do que da microestrutura menos relevante da história evidencia adequada compreensão da essência da mesma. Nossos resultados estão de acordo com a teoria de Kintsch e Van Dijk (1978) quanto à organização hierárquica das proposições: elementos de níveis mais altos da hierarquia (macroproposições) têm maior probabilidade de serem lembrados e incluídos em relatos (Kintsch, 1998).

Nos recontos da história deste estudo, as inferências foram mais freqüentes do que as reconstruções e as interferências, mostrando que as crianças extraíram também as idéias implícitas na história e, em geral, mantiveram-se fiéis ao significado original da mesma. Neste sentido, a compreensão de um texto não se resume à capacidade de memória, mas também à capacidade de inferir fatos que não são apresentados explicitamente no texto (Brandão \& Spinillo, 1998).

Elaboração de inferências é um componente fundamental da compreensão de textos lidos. Conforme Van Dijk (1980), dois conhecimentos são considerados prioritários à memorização e reconto de um texto: as estratégias 
Tabela 3

Matriz de correlações entre as avaliações de compreensão textual (Teste de Correlação de Pearson)

\begin{tabular}{|c|c|c|c|c|c|c|c|c|c|}
\hline & 1 & 2 & 3 & 4 & 5 & 6 & 7 & 8 & 9 \\
\hline 1. Idade & - & & & & & & & & \\
\hline 2. Compreensão questões total & 0,16 & - & & & & & & & \\
\hline 3. Memória eventos & 0,08 & $0,85^{* *}$ & - & & & & & & \\
\hline 4. Compreensão Inferencial & 0,20 & $0,89 * *$ & $0,53 * *$ & - & & & & & \\
\hline 5. Proposições & $0,24 *$ & $0,50 * *$ & $0,49 * *$ & $0,40 * *$ & - & & & & \\
\hline 6. Macroproposições & $0,30 * *$ & $0,52 * *$ & $0,51 * *$ & $0,41 * *$ & $0,91 * *$ & - & & & \\
\hline 7. Microproposições & 0,12 & $0,38^{* *}$ & $0,37 * *$ & $0,30 * *$ & $0,89 * *$ & $0,62 * *$ & - & & \\
\hline 8. Inferências & 0,08 & 0,12 & 0,16 & 0,05 & $0,25^{*}$ & 0,19 & $0,26 *$ & - & \\
\hline 9. Interferência & 0,08 & 0,06 & 0,02 & 0,08 & 0,17 & 0,12 & 0,19 & $-0,07$ & - \\
\hline 10. Reconstruções & 0,12 & 0,01 & $-0,03$ & 0,05 & $0,26 *$ & $0,24 *$ & $0,23 *$ & $0,25^{*}$ & $-0,01$ \\
\hline
\end{tabular}

$* p<0,05 ; * * p<0,01$

(processamentos online, dependentes do contexto, dirigidas a um objetivo) e os modelos mentais (relacionam o texto com o conhecimento prévio do indivíduo, suas crenças). Como os esquemas e os modelos mentais são individuais, criados a partir da vivência de cada um, e como os fatos são lembrados através desses esquemas individuais, a história evocada nunca é exatamente igual à história lida. Isso acontece, segundo Leffa (1996), devido a dois fatores: 1) já no ato de compreensão, o leitor está contribuindo com a sua experiência para a percepção do que lê, 2) o lapso de tempo entre a compreensão e a evocação também contribui para modificar a história de acordo com os esquemas individuais.

As duas formas usadas para avaliação da compreensão de leitura (reconto de história e questionário de múltipla escolha) estavam correlacionadas entre si, mostrando que, apesar de apresentarem exigências cognitivas diferentes, ambas avaliam uma habilidade comum, a compreensão de leitura textual. As habilidades compreensivas da amostra estudada parecem melhores quando avaliadas através do questionário sobre a história. Sabe-se que a tarefa de responder a perguntas é pontual, pois focaliza determinadas informações e partes do texto, sem que seja preciso selecionar as idéias mais importantes. As opções de resposta a uma questão específica facilitam sua execução, ativando um processo de reconhecimento. Tarefas de reconhecimento são utilizadas para detectar informações armazenadas, sem os possíveis vieses de uma tarefa de evocação, como o reconto.

Segundo Brandão e Spinillo (1998, 2001), recontar uma história é uma atividade de compreensão global que considera o texto como um todo, sendo também uma atividade de produção de outro texto, requerendo atenção a um modelo apresentado. Ao reproduzir, é preciso selecionar aspectos relevantes do texto original a serem reproduzidos, bem como as relações essenciais entre eles. O processo de evocação também faz uma seleção dos fatos armazenados na memória para criar a retórica pessoal de quem reconta. Brandão e Spinillo $(1998,2001)$ concluem que a reprodução de textos requer estabelecer dois níveis de relação: uma entre textos (texto que está sendo produzido no reconto e o texto original) e outra intra-texto (relações entre os enunciados do texto que está sendo produzido).

Na análise comparativa do desempenho em compreensão de leitura textual entre as séries, constatou-se que alunos da $3^{\underline{a}}$ série relataram mais proposições da microestrutura menos relevante da história e apresentaram desempenho superior no total do teste de compreensão de questões e nas questões de memória para eventos descritos na história do que alunos da $2^{\underline{a}}$ série. É interessante ressaltar que tanto o reconto como as respostas às questões evidenciaram o mesmo aspecto: as crianças de $3^{\underline{a}}$ série mostraram melhor memorização para aspectos pontuais da história. No reconto, relataram mais detalhes, e nas questões, responderam melhor a fatos específicos da história. Não foram encontradas diferenças significativas no relato das macroproposições (idéias essenciais), nem nas respostas a questões que exigiam compreensão da situação de relações entre eventos.

O melhor desempenho nas tarefas de compreensão textual das crianças da $3^{\underline{a}}$ série pode decorrer do aumento das habilidades lingüísticas ou metalingüísticas e de processos cognitivos, como memória e atenção, durante o desenvolvimento e a escolaridade. Segundo Brown, (1979, citado por Gerber, 1996), o ingresso na situação escolar cria exigências relacionadas à tarefa que requerem uso de memória declarativa, envolvendo conhecimento e controle deliberados dos meios de aprendizagem. Morrison (1987, citado por Flavell et al., 1999) constatou que crianças com um ano a mais de esco- 
la, mas da mesma idade que as outras crianças, tinham desempenho superior em recordação e uso de estratégias de memória. Tais estratégias podem facilitar o acesso a mecanismos de memória de curto prazo ou memória episódica necessários para o reconto de histórias (Parente et al., 1999a). Além disso, não há dúvidas de que, com o decorrer da escolarização, a criança é exposta a textos escritos cada vez mais longos, influenciando diretamente a compreensão leitora.

O uso de estratégias metacognitivas, como estabelecer um objetivo para a leitura e monitorar a compreensão de acordo com este objetivo (Kato, 1999), desenvolve-se definitivamente ao longo das séries iniciais (Leffa, 1996). Crianças da $3^{\underline{a}}$ série seriam mais hábeis no uso de estratégias metacognitivas do que as da $2^{\underline{a}}$ série, pois, para Leffa (1996), a metacognição correlaciona-se com a proficiência em leitura.

As crianças de $2^{\underline{a}}$ e $3^{\underline{a}}$ séries não apresentaram diferenças estatisticamente significativas no reconto da macroestrutura da história, apesar de as médias das últimas terem sido muito superiores. Isso pode ser devido aos elevados desvios-padrão apresentados nesta medida, evidenciando as discrepâncias de desempenho intra-séries. Por outro lado, observa-se uma correlação positiva entre idade (medida em meses) e o relato de macroproposições. Esses resultados podem sugerir que a capacidade de extrair informações da macroestrutura (idéias essenciais) é mais dependente do desenvolvimento, enquanto que a retenção de maior número de detalhes é mais sensível ao impacto dos anos iniciais de escolarização.

Sabe-se que o recontar de histórias, apesar de ser desenvolvido na escola, não depende exclusivamente da escolarização. A alfabetização contribui para o desenvolvimento de habilidades narrativas, porém, o desenvolvimento não está concluído com a aquisição da leitura e escrita e nem é nivelado por ela, uma vez que os anos escolares após a alfabetização são importantes para o aprimoramento da habilidade de contar histórias (Spinillo, 2001). Brandão e Spinillo (1998) apontaram que a capacidade da criança resumir e recontar é bastante influenciada por hábitos familiares de contar histórias. Segundo Spinillo (2001), as interações no meio familiar e as situações rotineiras de que a criança participa contribuem para o desenvolvimento da habilidade de contar histórias. Esta habilidade, acrescenta a autora, apresenta um desenvolvimento gradual, cujo percurso é influenciado por uma série de fatores, como idade, escolaridade e interações sociais diversas. As práticas sociais relativas à leitura e escrita transcendem não só os limites da escola como, também, precedem o ingresso da criança no sistema de ensino formal (Correa, 2001).

Por fim, a correlação positiva entre número de inferências e porcentagem de proposições e de microproposições menos relevantes da história relatadas sugere que, à medida que a criança dedica esforços para descrever os detalhes de uma história, ela passa a enunciar também as inferências feitas durante a leitura, ou seja, as idéias subentendidas na história. Em geral, as crianças mais fluentes na compreensão e reconto da estrutura textual (proposições originais da história) foram as que fizeram mais inferências e recontaram a história mais detalhadamente. A maior parte das proposições da história (62,3\%) fazia parte do que consideramos como microestrutura menos relevante, justificando a alta correlação entre estas duas medidas.

Em suma, os resultados deste estudo permitiram evidenciar que, durante os primeiros anos de escolarização ocorre uma melhora marcante da memorização e de sua incorporação no relato das crianças. Já a retenção das idéias essenciais não se mostrou sensível ao aumento de escolarização, mas sim às variações de idade das crianças.

Uma limitação desse estudo é a participação de crianças de uma mesma escola. É possível que o método pedagógico adotado tenha enfatizado a retenção de novas informações e pouco a extração de idéias essenciais. Provavelmente os resultados encontrados possam ser diferentes quando as atitudes dos educadores favorecerem os processos de captação de idéias principais de um texto, e também possam ser revertidos com intervenções específicas. No momento, essa pesquisa contribui aos estudos sobre o desenvolvimento de compreensão textual, apontando que durante os primeiros anos de escolarização é possível ocorrer uma dissociação no desenvolvimento da capacidade de reter e recontar detalhes em relação à capacidade de extrair as idéias principais de uma história.

\section{Referências}

Alégria, J., Leybaert, J., \& Mousty, P. (1997). Aquisição da leitura e distúrbios associados: avaliação, tratamento e teoria. In J. Grégoire \& B. Piérart (Orgs.), Avaliação dos problemas de leitura: os novos modelos teóricos e suas implicações diagnósticas (pp. 105-124). Porto Alegre: Artes Médicas.

Boruchovitch, E. (2001). Algumas estratégias de compreensão em leitura de alunos do Ensino Fundamental. Psicologia Escolar e Educacional, 5(1), 19-25.

Braibant, J. (1997). A decodificação e a compreensão: dois componentes essenciais da leitura no $2^{\underline{0}}$ ano primário. In J. Grégoire \& B. Piérart (Orgs.), Avaliação dos problemas de leitura: os novos modelos teóricos e suas implicações diagnósticas (pp. 167-187). Porto Alegre: Artes Médicas.

Brandão, A. C. P., \& Spinillo, A. G. (1998). Aspectos gerais e específicos na compreensão de textos. Psicologia: Reflexão e Crítica, 11(2), 253-272.

Brandão, A. C. P., \& Spinillo, A. G. (2001). Produção e compreensão de textos em uma perspectiva de desenvolvimento. Estudos de Psicologia, 6(1), 5162.

Cadilhac, C., Virbel, J., \& Nespoulous, J. L. (1997). Compréhension et mémorisation de textes de différentes structures par des sujets normaux et pathologiques: “le vieil homme”. Isbergues: L’Ortho-Edition.

Cain, K. (1999). Ways of reading: How knowledge and use of strategies are related to reading comprehension. British Journal of Developmental Psychology, 17, 295-312.

Carmona, M. B., González, J. M. I., \& Gómez, A. R. (1992). Psicología del lenguage. Investigación y teoría. Madrid: Trotta.

Chiele, L. K. (1996). A compreensão em leitura como indicadora do nível de inteligência. Dissertação de Mestrado não-publicada, Pontifícia Universidade Católica do Rio Grande do Sul, Porto Alegre.

Correa, J. (2001). Aquisição do sistema de escrita por crianças. In J. Correa, A. Spinillo, \& S. Leitão (Orgs.), Desenvolvimento da linguagem: escrita e textualidade (pp. 19-70). Rio de Janeiro: NAU/FAPERJ.

Denhière, G., \& Baudet, S. (1992). Lecture compréhension de texte et science cognitive. Paris: Presses Universitaires de France. 
Dias, M. G. B. B. (2000). Raciocínio lógico, experiência escolar e leitura com compreensão. Psicologia: Teoria e Pesquisa, 16(1), 55-62.

Dias, M. G. B. B., Morais, E. P. M., \& Oliveira, M. C. N. P. (1995). Dificuldades na compreensão de textos: uma tentativa de remediação. Arquivos Brasileiros de Psicologia, 47(4), 13-24.

Ellis, A. W. (1995). Leitura, escrita e dislexia: uma análise cognitiva. Porto Alegre: Artes Médicas.

Engle, R. W., Cantor, J., \& Carullo, J. J. (1992). Individual differences in working memory and comprehension: a test of four hypotheses. Journal of Experimental Psychology: Learning, Memory, and Cognition, 18(5), 972992.

Favero, M. E., \& Trajano, A. A. (1998). A leitura do adolescente: mediação semiótica e compreensão textual. Psicologia: Teoria e Pesquisa, 14(3), 229240

Flavell, J. H., Miller, P. H., \& Miller, S. A. (1999). Desenvolvimento cognitivo. Porto Alegre: Artes Médicas.

Gaux, C., \& Gombert, J. E. (1999). Implicit and explicit syntactic knowledge and reading in pre-adolescents. British Journal of Developmental Psychology, 17, 169-188.

Gerber, A. (1996). Problemas de aprendizagem relacionados à linguagem: sua natureza e tratamento. Porto Alegre: Artes Médicas.

Goes, M. C. R., \& Aragão, R. M. R. (1992). Níveis de compreensão da linguagem escrita em crianças com atraso escolar. Arquivos Brasileiros de Psicologia, 44(3/4), 71-88.

Graesser, A. C., Swamer, S. S., Baggett, W. B., \& Sell, M. A. (1996). New models of deep comprehension. In B. K. Britton \& A. C. Graesser (Orgs.), Models of understanding text (pp. 1-32). New Jersey: Erlbaum.

Jou, G. I. (2001). As habilidades cognitivas na compreensão da leitura: uma proposta de intervenção no contexto escolar. Tese de Doutorado nãopublicada, Universidade Federal do Rio Grande do Sul, Porto Alegre.

Kato, M. A. (1999). O aprendizado da leitura. São Paulo: Martins Fontes.

Kintsch, W. (1977). On comprehending stories. In M. Just \& P. Carpenter (Orgs.), Cognitive process in comprehension (pp. 33-62). Hillsdale: Erlbaum.

Kintsch, W. (1988). The role of knowledge in discourse comprehension: a construction-integration model. Psychological Review, 95(2), 163-182.

Kintsch, W. (1998). Comprehension: a paradigm for cognition. Nova York: Cambridge University Press.

Kintsch, W., \& van Dijk, T. A. (1978). Toward a model of text comprehension and production. Psychological Review, 85(5), 363-394.

Kopcke Filho, H. (1997). Estratégias para desenvolver a metacognição e a compreensão de textos teóricos na universidade. Psicologia Escolar e Educacional, 1(2-3), 59-67.

Leffa, V. J. (1996). Aspectos da leitura: uma perspectiva psicolingüística. Porto Alegre: Sagra-Luzzatto.

McBridge, C., Manis, F. R., Seidenberg, M. S., Custodio, R. G., \& Doi, L. M. (1993). Print exposure as a predictor of word reading and reading comprehension in disabled and nondisabled readers. Journal of Educational Psychology, 85(2), 230-238.
Mello, M. T. O. P. (1988). Efeito de um treino de leitura de um material de história do Brasil para crianças de 8 a 10 anos quanto a inteligibilidade e compreensão de texto. Estudos de Psicologia, 5(2), 112-126.

Morais, J. (1996). A arte de ler. São Paulo: Editora da Universidade Estadual Paulista.

Nation, K., \& Snowling, M. J. (1998). Semantic processing and development of word-recognition skills: evidence from childrem with reading comprehension difficulties. Journal of Memory and Language, 39, 85-101.

Parente, M. A. M. P., Capuano, A., \& Nespoulous, J. (1999a). Ativação de modelos mentais no recontar de histórias por idosos. Psicologia: Reflexão e Crítica, 12(1), 157-172.

Parente, M. A. M. P., Saboskinski, A. P., Ferreira, E., \& Nespoulous, J. (1999b). Memória e compreensão da linguagem no envelhecimento. Estudos Interdisciplinares do Envelhecimento, 1, 57-76.

Rego, L. L. B. (1995). Diferenças individuais na aprendizagem inicial da leitura: papel desempenhado por fatores metalingüísticos. Psicologia: Teoria e Pesquisa, 11(1), 51-60.

Rocha, R. (1997). A coisa. In C. S. Carvalho \& M. D. Baraldi (Orgs.), Construindo a escrita: leitura e interpretação de textos (pp. 86-95). São Paulo: Ática.

Rodrigues, A. A., Dias, M. G. B. B., \& Roazzi, A. (2002). Raciocínio lógico na compreensão de texto. Estudos de Psicologia, 7(1), 117-132.

Ruíz-Vargas, J. M. (1995). Psicología de la memoria. Madri: Alianza Psicología.

Salles, J. F., Parente, M. A. M. P., Alexandre, B., Xavier, C., \& Fernandes, J. (2001). Recontar de histórias por crianças: instrumentos de avaliação da compreensão de leitura. Letras de Hoje, 36(3), 529-535.

Salles, J. F., \& Parente, M. A. M. P. (2002). Processos cognitivos na leitura de palavras em crianças: relações com compreensão e tempo de leitura. Psicologia: Reflexão e Crítica, 15(2), 321-331.

Santos, A. A. A. (1990). Compreensão em leitura na universidade: um estudo comparativo entre dois procedimentos de treino. Estudos de Psicologia, $7(2), 39-53$.

Santos, A. A. A. (1991). Desempenho em leitura: um estudo diagnóstico da compreensão e hábitos de leitura entre universitários. Estudos de Psicologia, 8(1), 6-19.

Spinillo, A. G. (2001). A produção de histórias por crianças: a textualidade em foco. In J. Correa, A. Spinillo, \& S. Leitão (Orgs.), Desenvolvimento da linguagem: escrita e produção textual (pp. 73-116). Rio de Janeiro: NAU/FAPERJ.

Stein, N. L., \& Glen, C. G. (1976). An analysis of story comprehension in elementary school children. In R. Freedle (Org.), New directions in discourse processing (pp. 53-120). New Jersey: Norwood.

Swanson, H. L., \& Alexander, J. E. (1997). Cognitive processes as predictors of word recognition and reading comprehension in learning-disabled and skilled readers: revisiting the specificity hypothesis. Journal of Eduactional Psychology, 89(1), 128-158.

van Dijk, T. A. (1980). Story comprehension: an introduction. Poetics, 9, 1-21.

Waters, G. S., \& Caplan, D. (1996). The measurement of verbal working memory capacity and its relation to reading comprehension. The Quarterly Journal of Experimental Psychology, 49A(1), 51-79.

Jerusa Fumagalli de Salles, doutoranda em Psicologia pela Universidade Federal do Rio Grande do Sul, é fonoaudióloga, especialista em Linguagem pelo Conselho Federal de Fonoaudiologia e professora no Curso de Psicologia, Centro Universitário Franciscano. Endereço para correspondência: Rua Venâncio Aires, 1110/ 202; Santa Maria, RS; CEP 97010-000. Fones: (55) 3026-3583 e (55) 9952-1414. E-mail: jerusa@via-rs.net Maria Alice de Mattos Pimenta Parente, doutora em Psicologia Escolar pela Universidade de São Paulo e pósdoutora pelo Centre de Recherche du Centre Hôspitalier “Côte-des-Neiges” da Universidade de Montreal, Canadá e pelo Laboratório de Neuropsicolingüística Jacques Lordat da Universidade Toulouse Le Mirail, França, é fonoaudióloga e professora no Instituto de Psicologia, Universidade Federal do Rio Grande do Sul. 


\section{Apêndice A}

\section{Estrutura proposicional da história "A coisa"}

A casa do avô 1/ de Pedro 2/ era uma dessas casas antigas 3/, grandes 4/, que têm dois andares 5/ e mais um porão 6/ velho 7/. Um dia Pedro resolveu ir lá embaixo 8/ procurar uns patins 9/. Pegou uma lanterna 10/ e foi descendo as escadas 11/ com cuidado 12/. No que foi, voltou 13/ aos berros 14/: - Fantasma! 15/ Uma coisa 16/ horrível! 17/ Um monstro 18/ com uma luz 19/ saindo da barriga 20/. Ninguém acreditou! 21/ Onde é que já se viu monstro com luz saindo da barriga? 22/ Então o vovô foi ver o que havia 23/. E voltou 24/ correndo 25/ como o Pedro 26/: — A Coisa! 28/ — ele gritava 27/— A Coisa! 28/ É muito 30/ alta 29/, com os olhos brilhantes, 31/ como se fossem de vidro! 32/ E na cabeça uns tufos 33/ espetados 34/ para todos os lados! 35/ Dona Julinha, a avó do Pedro, 36/ era a única 38/ que não estava impressionada 37/ Então ela foi ver o que estava acontecendo 39/ Foi descendo as escadas 40/ devagar, 41/abrindo as janelas 42/ que encontrava 43/. A família veio atrás 44/ toda assustada 45/, morrendo de medo 46/ do monstro 47/, fantasma 48/, fosse lá o que fosse 49/.

Até que chegaram lá embaixo 50/ e Dona Julinha abriu a última janela 51/. Então todos começaram a rir 52/, muito 54/ envergonhados 53/. A Coisa era... um espelho! 55/ Cada um que descia as escadas, 56/ no escuro, 57/ via uma coisa 58/ diferente 60/ no espelho 59/. E todos eles pensavam que tinham visto... a Coisa. 61/

OBS: As proposições em negrito fazem parte da macroestrutura da história. 


\section{Apêndice B}

Avaliação da compreensão de leitura - Questões:

1. O que Pedro estava procurando no porão?

a) ( ) uma lanterna

b) ( ) seus brinquedos

c) ( ) um espelho

d) ( ) uns patins

2. Como era a casa dos avós de Pedro?

a) ( ) pequena e nova

b) ( ) de madeira

c) ( ) grande e antiga

d) ( ) branca e com janelas grandes

3. Como era a Coisa que Pedro tinha visto no porão?

a) ( ) tinha uma luz saindo da barriga

b) ( ) horrível e com cabelos espetados

c) ( ) alta e com olhos brilhantes

d) ( ) feia e de cabelos vermelhos

4. O que era, na verdade, a Coisa?

a) ( ) um fantasma

b) ( ) um monstro

c) ( ) um lençol

d) ( ) um espelho

5. Quem é que esclareceu o mistério da Coisa?

a) ( ) o avô de Pedro

b) ( ) a avó de Pedro

c) ( ) o próprio Pedro

d) ( ) o tio de Pedro

6. Por que Pedro pegou uma lanterna para ir até o porão?

a) ( ) porque ele não queria que ninguém o incomodasse ao brincar com a lanterna.

b) ( ) porque lá embaixo estava muito escuro.

c) ( ) porque o porão é o lugar de guardar a lanterna.

d) ( ) porque sua avó mandou-o trocar as lâmpadas do porão.

7. Por que todos começaram a rir e ficaram envergonhados após a avó de Pedro abrir todas as janelas do porão?

a) ( ) porque a avó de Pedro tinha dado um sermão em todos eles.

b) ( ) porque tudo estava muito sujo no porão.

c) ( ) porque eles viram que a Coisa, na verdade, era um espelho.

d) ( ) porque a avó de Pedro havia caído na escada que desce para o porão.

8. Por que apenas o Pedro viu um monstro com uma luz saindo da barriga, ao descer no porão?

a) ( ) porque esse monstro só apareceu para ele.

b) ( ) porque o monstro só queria amedrontar o Pedro.

c) ( ) porque lá embaixo havia um teletub.

d) ( ) porque apenas o Pedro desceu as escadas segurando uma lanterna, que refletiu no espelho.

9. Porque o avô de Pedro via uma coisa com olhos brilhantes, como se fossem de vidro?

a) ( ) porque ele usava óculos, que refletiram no espelho parecendo um monstro.

b) ( ) porque ele estava sonhando.

c) ( ) porque lá embaixo havia vidros quebrados.

d) ( ) porque a coisa tinha olhos muito grandes.

10. Porque cada um que descia a escada via uma coisa diferente?

a) ( ) porque havia vários fantasmas lá embaixo.

b) ( ) porque a Coisa se escondia atrás dos móveis do porão.

c) ( ) porque o que cada um via era sua própria imagem refletida no espelho.

d) ( ) porque todos eles estavam sonhando. 